\title{
Endoscopic resection of prepyloric diaphragm in an adult
}

Prepyloric diaphragm is a rare anatomic anomaly in adults and can cause gastric outlet obstruction. A 33-year-old man presented with postprandial epigastric distress and a 10-year history of repeated nonbilious vomiting. He was otherwise healthy with no medical history of peptic ulcer or caustic ingestion. Body mass index was 15.9.

Barium swallow test revealed linear antropyloric narrowing ( $\mathbf{F i g} \mathbf{1} \mathbf{1})$. Computed tomography scan showed prepyloric web of the distal gastric antrum, about $0.5 \mathrm{~cm}$ proximal to the pylorus ( $\mathbf{F i g . 2}$ ). Esophagogastroduodenoscopy demonstrated gastric outlet obstruction with a pinhole opening and a linear scar on the posterior wall of the antrum ( $>$ Fig. 3 ).

Direct endoscopic resection was performed in a radial fashion using a HookKnife (Olympus, Tokyo, Japan) until the circular muscle was cut open completely ( Video 1). A normal pylorus was exposed and the prepyloric diaphragm was resected thoroughly ( $>$ Fig. 4 ).

The patient's symptom resolved immediately after endoscopic therapy and he was discharged uneventfully 3 days later. Esophagogastroduodenoscopy and barium swallow test were repeated 3 months later and revealed no gastric outlet obstruction ( $\mathbf{F i g . 5}$ ).

The etiology of prepyloric diaphragm is controversial in adults as to whether it is congenital or acquired [1]. The association of a linear scar near the prepyloric diaphragm in the current case indicates that it was possibly caused by scarring from a gastric ulcer. Prepyloric diaphragm can be managed with surgical or endoscopic intervention. Endoscopic methods include balloon dilation, resection with a snare, needle knife, or laser $[2,3]$. However, there is no standard regarding the width and depth required for sufficient resection of prepyloric diaphragm. Direct endoscopic resection until the circular muscle is cut open without building a submucosal tunnel has been used for congenital pyloric stenosis, achalasia, and other benign strictures $[4,5]$. We chose this method to achieve maximum alleviation of obstruction and minimize the possibility of re-obstruction. Endoscopic resection can be performed safely in patients with prepyloric diaphragm.

Endoscopy_UCTN_Code_TTT_1AO_2AH

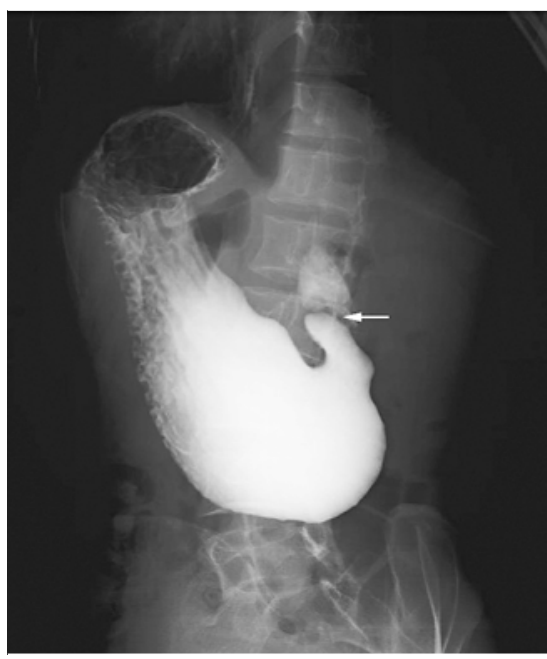

- Fig. 1 Barium swallow test showed linear antropyloric narrowing (arrow).

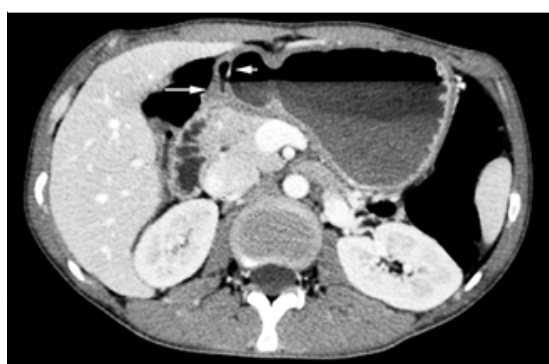

- Fig. 2 Computed tomography scan showed prepyloric diaphragm (short arrow) proximal to the pylorus (long arrow).

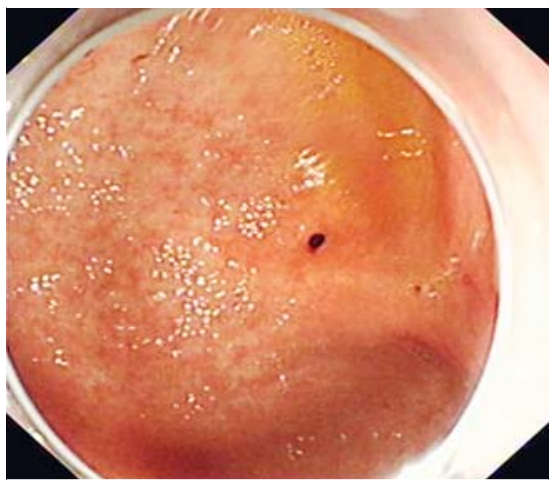

- Fig. 3 Esophagogastroduodenoscopy demonstrated gastric outlet obstruction with a pinhole opening and a linear scar on the posterior wall of the antrum. 

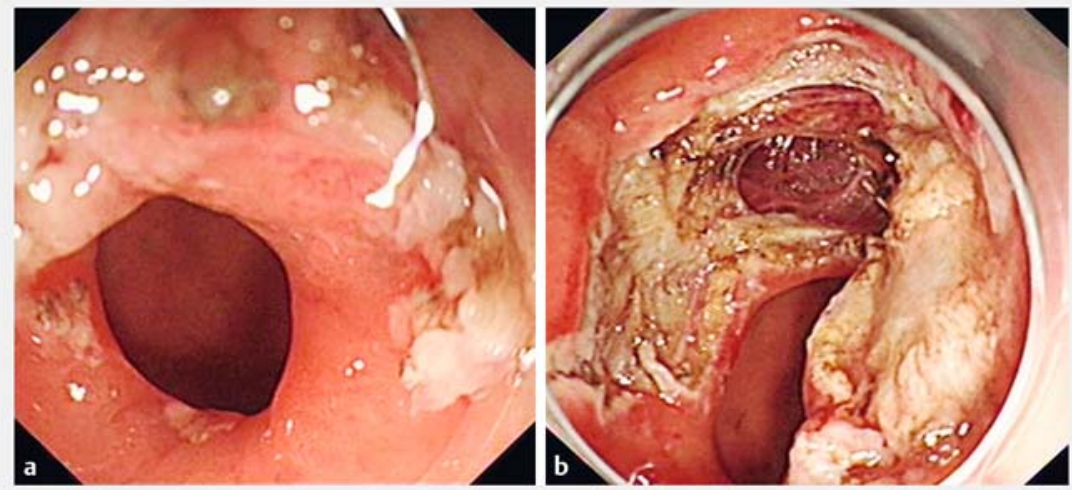

\section{References}

[1] Gomes RM, Kudchadkar J, Peshwe $\mathrm{H}$ et al. Gastric outlet obstruction secondary to adult gastric antral web. Ann Gastroenterol 2013; 26: 371

[2] Gul W, Abbass K, Markert RJ et al. Gastric antral web in a 103-year-old patient. Case Rep Gastrointest Med 2011; 2011: 957060

[3] Salah W, Baron TH Sr. Gastric antral web: a rare cause of gastric outlet obstruction treated with endoscopic therapy. Gastrointest Endosc 2013; 78: 450

[4] Ibarguen-Secchia E. Endoscopic pyloromyotomy for congenital pyloric stenosis. Gastrointest Endosc 2005; 61: 598-600

- Fig. 4 Endoscopic resection of the prepyloric diaphragm. a A normal pylorus was found distal to the prepyloric diaphragm. $\mathbf{b}$ The prepyloric diaphragm was resected thoroughly.

[5] Liu W, Zeng HZ, Chen HL et al. Open peroral endoscopic myotomy (O-POEM) for the treatment of achalasia. Dis Esophagus 2017; 30: $1-2$
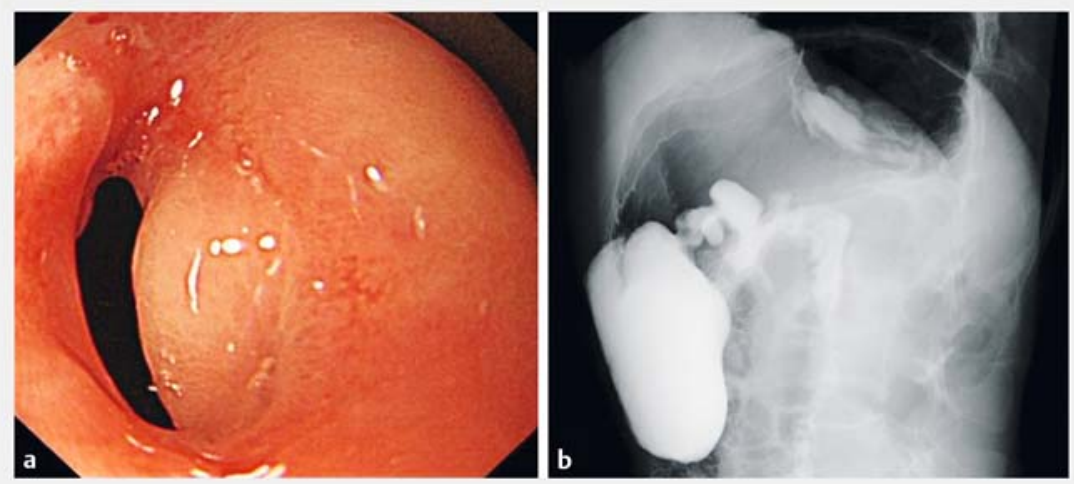

- Fig. 5 Follow-up 3 months after endoscopic treatment showed no gastric outlet obstruction. a Esophagogastroduodenoscopy. b Barium swallow.

\section{Acknowledgment}

The authors want to thank the National key R\&D Program of China (2017YFC0112305).

\section{Competing interests}

None

The authors

\section{Lin-Jie Guo, Chun-Cheng Wu, Bing Hu}

Department of Gastroenterology, West China Hospital, Sichuan University, Chengdu, China

\section{Corresponding author}

\section{Bing Hu, MD}

Department of Gastroenterology, West China Hospital, Sichuan University, 37 Guoxue Road, Chengdu, Sichuan Province 610041, China

Fax: +86-028-85423387

hubingnj@163.com

\section{Bibliography}

DOI https://doi.org/10.1055/a-0800-8568

Published online: 23.1.2019

Endoscopy 2019; 51: E75-E76

(c) Georg Thieme Verlag KG

Stuttgart · New York

ISSN 0013-726X

\section{ENDOSCOPY E-VIDEOS}

https://eref.thieme.de/e-videos

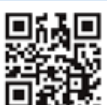

Endoscopy E-Videos is a free access online section, reporting on interesting cases and new techniques in gastroenterological endoscopy. All papers include a high quality video and all contributions are freely accessible online.

This section has its own submission website at

https://mc.manuscriptcentral.com/e-videos 